\title{
AUTOESTIMA, ESTRESSE E A RELAÇÃO COM A CRIANÇA INTERIOR
}

\author{
Graça MARTINI* \\ Ana Lúcia de Moraes HORTA*
}

RESUMO: O objetivo desse estudo foi compreender a relação da criança interior com a autoestima e com o estresse do participante do Curso Cuidando do Cuidador. Foram avaliados onze participantes por meio do grupo focal, realizado após a semana de curso. Para analisar as opinióes coletadas foi utilizado o programa Qualiquantisoft, um software desenvolvido por Lefèvre e Lefèvre, cuja metodologia é denominada de Discurso do Sujeito Coletivo (DSC). Mediante análise foi comprovado que, após a participaçáo do curso, os sujeitos alcançaram melhora em sua autoestima, reduziram estresse a partir do encontro com a criança interior. Os resultados apontaram, também, para uma maior propensão à resiliência.

PALAVRAS-CHAVES: Autocuidado. Autoestima. Estresse psicológico. Terapia.

\section{Introdução}

As relaçôes familiares, muito influenciam na autoestima e no estresse de seus membros. Como exemplo disso, Fiamenghi Junior e Messa

\footnotetext{
* Doutora em Terapia de família e coordenadora e intervisora do Polo Formador. CAIFCOM - Centro de Ensino, Pesquisa e Atendimento do Indivíduo, Família e Comunidade e Faculdade Evangélica do Meio Norte. Porto Alegre - RS - Brasil. 90550070. Terapeuta Comunitária e Membro do Grupo Gestor. ABRATECOM- Associação Brasileira de Terapia Comunitária Integrativa. Fortaleza - CE - Brasil. 60333-765. (Conselho Fiscal - 2013/2015 e Vice-Presidente - 2015/2017). Psicopedagoga. Prefeitura de Londrina - Secretaria Municipal de Educação. Londrina - PR - Brasil. 86010-040 gracapedrazzi@gmail.com

** UNIFESP - Universidade Federal de São Paulo. Escola Paulista de Enfermagem. São Paulo - SP - Brasil.04021-001 - analuciahorta18@gmail.com
} 
(2007) apontam que a maneira como cada família supera uma crise ou problemas, em geral, depende de seus recursos e da intensidade desses eventos. Trata-se de um momento, em que coexistem a possibilidade de crescimento, a maturidade e o fortalecimento e o consequente risco de transtornos psíquicos, tanto nos indivíduos como dos vínculos. Alguns pontos determinam o significado da experiência em cada família: a capacidade de enfrentar mudanças repentinas, a história de cada familiar, as situaçóes controversas atravessadas anteriormente e a maneira que foram solucionadas, o sistema de crenças, a existência ou não de um lugar para a criança com deficiência dentro do sistema familiar, o grau de expectativas, a capacidade e qualidade de informação do grupo familiar, o nível cultural e socioeconômico da família, a presença ou não da rede de apoio, a capacidade da família de se relacionar com terceiros, de buscar amparo e a possibilidade de que a família esteja enfrentando outro momento marcante paralelo ao do nascimento da criança.

Pereira (2008) concebe a infância como período que contém algo mágico, em função da capacidade de criação e imaginação dos indivíduos. A autora apresenta, então, a noção de criança interior, como o potencial de todas as infâncias que ainda permanecem no interior de cada indivíduo. Segundo Pereira (2008), o mundo infantil remete a um universo de espontaneidade, curiosidade, brincadeiras, imaginação e lembranças, sendo estas não apenas de coisas boas ou positivas, mas também de recordaçôes que feriram, em suma, dos registros gravados internamente como herança da história individual. Sendo assim, o mundo que envolve a criança remonta aos fatos reais e simbólicos, que foram salvos na memória afetiva.

Nota-se que o conceito da criança interior foi impulsionado, principalmente, pela popularização na cultura $p o p$ das últimas décadas, entretanto, defende-se que essa concepção é atemporal e contemporânea, simultaneamente. Pereira (2008) cita Abrams ao desenvolver as origens do motivo da criança interior, alegando que, no princípio, surgiram os deuses-crianças, junto às religióes solares e de adoraçáo à natureza, que originaram as crianças mitológicas divinas, como o exemplo da fábula de Rômulo e Remo, que determina o surgimento da civilização romana. Atualmente, existe a noção da "criança Cristo", em razáo do conceito messiânico dos hebreus. Na Idade Média, havia a "criança Filosofal", devido aos alquimistas pensarem a existência de uma criança interior anímica, que proporcionaria a síntese dos opostos e há, também, o conceito de "criança Krishna", tal qual uma presença divina, cuja concepçáo vale para o Oriente (PEREIRA, 2008, p.9). 
Ao publicar a obra The Psychology of the Child Archetype, em 1959, Jung manifesta o conceito da criança interior, definida como um símbolo da psique, uma totalidade, uma figura que possibilita o acesso como uma espécie de ponte entre os planos coletivo e pessoal. Os arquétipos representam as imagens primordiais ou psíquicas do inconsciente coletivo e este último representa uma seção do inconsciente individual, que resulta da experiência ancestral da espécie, isto é, há nele material psíquico não provido da experiência pessoal ou individual (PRADO, 2013). Os arquétipos abarcam conteúdos psíquicos que carregam carga afetiva, surgidos por meio das repetiçóes de uma mesma experiência durante várias geraçóes, que Prado (2013) aponta serem heranças genéticas dos ancestrais, que pertenceram à determinada civilização e que passaram pelas mesmas experiências.

O Curso Cuidando do Cuidador propôs uma volta consciente ao passado, em que cada participante revisitou a sua história familiar, por meio do resgate e acolhimento da criança interior. Portanto, o objetivo desse estudo foi compreender a relaçấo da criança interior com a autoestima e com o estresse do participante do Curso Cuidando do Cuidador.

\section{Método}

Este é um estudo descritivo qualitativo que foi realizado no Ceará, em lugar reservado. Utilizou-se o grupo focal como metodologia. O Curso Cuidando do Cuidador foi ministrado pelo seu idealizador.

Foram incluídos os inscritos no Curso Cuidando do Cuidador, que assinaram o Termo de Consentimento Livre e Esclarecido. Para esta pesquisa não foram estabelecidos limites de idade ou gênero e não houve critérios de exclusão. O estudo foi aprovado pelo Comitê de Ética da Plataforma Brasil pelo CEP 958272.

Para o estudo qualitativo foram convidados os vinte e seis participantes do Curso Cuidando do Cuidador, que assinaram o Termo de Consentimento Livre e Esclarecido. Os participantes do Grupo Focal foram definidos, espontaneamente, ao final do Curso, em que onze pessoas se dispuseram a participar.

A idade dos participantes variou de 26 a 79 anos de ambos os sexos.

No primeiro dia, antes do início das atividades do curso foi entregue um envelope a cada participante da pesquisa contendo: Formulário de Identificação; Termo de Consentimento Livre e Esclarecido. Após o término do curso foi realizada a avaliação final do curso e o grupo focal. 
O grupo focal teve como questão norteadora: Conte como foi a experiência de participar do Curso Cuidando do Cuidador em relaçáo à autoestima, estresse e a relaçáo com a criança interior.

Como forma de registro, foi utilizado o recurso da filmagem. O Grupo Focal contou com dois observadores convidados.

\section{Análise dos dados}

A análise qualitativa foi realizada por meio da técnica do Discurso do Sujeito Coletivo (DSC). O Discurso do Sujeito Coletivo (DSC) consiste em uma forma não matemática e não metalinguística de representar o pensamento de uma coletividade, o que faz mediante uma série de operaçôes sobre os depoimentos, que culmina em discursos-síntese, que reúne respostas de diferentes indivíduos, com conteúdo discursivo de sentido semelhante, o qual passa a expressar ou a representar a fala social ou o pensamento coletivo na primeira pessoa do singular.

Para a categorizaçáo dos dados coletados foi utilizado o Qualiquantisoft, que se trata de um software desenvolvido por Lefevre e Lefevre (2007), em parceria com a Sales \& Paschoal Informática, com o objetivo de facilitar a realização de pesquisas quali/quantitativas, nas quais é utilizada a técnica do Discurso do Sujeito Coletivo (DSC).

\section{Resultados qualiquantitativos}

Para esse artigo serão apresentados os dados quantitativos referentes ao perfil dos onze participantes do grupo focal e, em seguida, os resultados qualiquantitativos correspondentes aos três temas, suas categorias e trechos ilustrativos do Discurso do Sujeito Coletivo (DSC).

É importante considerar na construçáo do DSC, que mesmo tendo o grupo focal sido composto por homens e mulheres, optou-se por deixar todo DSC no feminino, utilizando-se da metáfora da «criança interior».

\section{Perfil dos Entrevistados}

- Abaixo dos 40 anos foram 03 entrevistados (27,3\%), de 40 a 50 foram 04 (36,4\%), de 50 a 60 foram 2 (18,2\%), mesmo número registrado em participantes acima dos 60 anos de idade, totalizando 11 entrevistados.

- Com relaçáo ao sexo dos participantes foram nove mulheres $(81,8 \%)$ e dois homens $(18,2 \%)$. 
- Dos onze entrevistados, sete eram casados $(63,6 \%)$ e quatro soltei$\operatorname{ros}(36,4 \%)$.

- Dos participantes do curso, sete possuíam filhos $(63,6 \%)$ e quatro não $(36,4 \%)$.

- Dos participantes, sete possuíam os pais vivos $(63,6 \%)$ e quatro não $(36,4 \%)$.

Com relação ao número e percentual de participantes do Curso Cuidando do Cuidador, segundo renda em salários mínimos, três apresentavam renda de até dois salários mínimos (27,3\%); três tinham a renda de quatro a seis salários mínimos $(27,3 \%)$, dois tinham renda acima de dez salários mínimos $(18,2 \%)$ e três não informaram $(27,3 \%)$.

A seguir serão apresentados três temas: vivência, significado e resultado do Curso Cuidando do Cuidador; Encontro da criança interior e a relação com a autoestima e o encontro da criança interior e a relação com o estresse, apresentando resultados reais acerca de indivíduos, que os vivenciaram.

\section{Tema 1: Vivência, significado e resultado do Curso Cuidando do Cuidador}

\section{Resultados Quantitativos}

Gráfico 1 - Proporção de ideias centrais frente ao Tema 1: Vivência, significado e resultado do Curso "Cuidando do Cuidador", Ceará, 2014

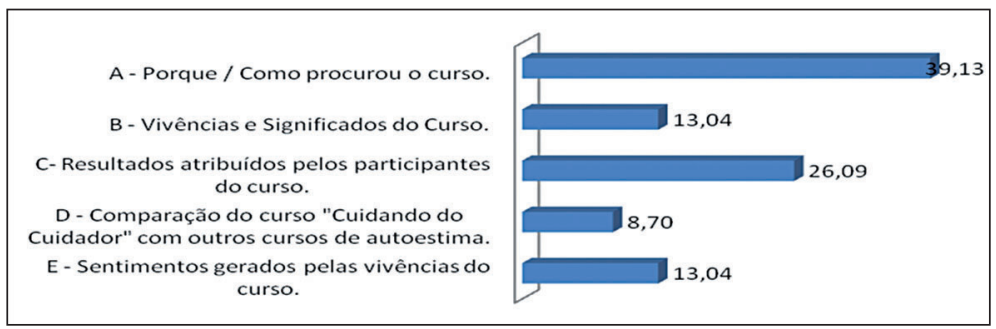

Fonte: Elaboração própria. 


\section{Resultados Qualitativos}

\section{- Por que / Como procurou o curso}

[...] quando eu vim pra cá, eu vim assim, pra me cuidar mesmo né? Aprender a conviver comigo e me capacitar a viver com o outro, normalmente as pessoas que chegam aqui nesse curso Cuidando do Cuidador são aquelas que estão com aquela criança machucada, aquela criança ferida, porque foi assim que eu cheguei aqui. (DSC A).

\section{- Vivências e significados do curso}

[...] então assim, a partir do segundo dia (de curso), eu entendi que na verdade, a minha motivaçáo de ajudar o outro, fez com que eu me permitisse cuidar de mim, que essa frase que eu amo e eu já falei pra todas as pessoas que eu conheço: é cuidando de mim que eu cuido do outro. E cuidando dos outros, eles também estão cuidando de mim.

O curso também traz muita dor, dor mesmo, física, corporal. [...] Todas as vezes que eu senti muita dor depois eu senti muita leveza. No sentindo assim, eu sei que está doendo, mas é necessário sentir isso para poder fazer a mudança. E que bom que eu consegui colocar muita coisa pra fora de ressentimentos, de mágoas, de raiva também, sentimento de não ser valorizada, nessa coisa física mesmo de não conseguir gritar muito ainda. Mas já estou falando mais alto então acho que estou conseguindo. [...] Saúde é movimento! Então se eu vou me estressando me encolhendo, me estressando, me paralisando: ai eu náo posso me movimentar porque vai doer meu pescoço, não posso fazer caminhada porque estou com um "negócio” inflamado. Então eu vou me encolhendo... Então saúde é movimento. E o que nos identifica aqui? Todos nós? Nós sacamos isso e nós demos um passo. (DSC B).

\section{- Resultados atribuídos pelos participantes do curso}

Todo esse trabalho aqui foi um trabalho de transformação, o ambiente aqui me produziu menos estresse, o que a gente conquistou aqui, vai conseguir me ajudar para eu viver melhor o estresse lá, não deixar que ele faça mal. Acho que todo mundo vai sair daqui transformado. Eu compreendi que eu não preciso levar ninguém nas costas, compreendi a minha história. Que foi a história dos meus antepassados, que 
a minha família levava tudo isso nas costas e hoje eu preciso tirar isso, eu não preciso mais [...] Eu nem sabia que eu tinha criança interior e agora ela é visível, pelo menos agora eu sei que ela existe, acho que isso vai acontecer naturalmente, eu acho que não precisa um esforço muito "forte". Eu acho que o processo que a gente viveu vai ficar, vai fluir. Aqui eu encontrei forças em como transmutar isso, sei que eu vou conseguir ativar o neocortex. (DSC C).

\section{- Comparaçáo do Curso "Cuidando do Cuidador” com outros cursos de autoestima}

[...] então eu fui pra ver, realmente foi muito bom, muito bom, mas eu deixei lá! Sai de lá e deixei lá! Então aqui, eu sinto um pouco diferente, é como se eu realmente tivesse conseguido um resgate dessa criança, com essa de hoje eu senti dificuldade, cansada e tudo (vivência da raiva e massagem), mas isso tudo foi muito bom para mim, eu acho que a gente deve fazer (as vivências) pra a gente poder realmente se reanimar, se levantar e começar e todos os dias, e aquilo que a gente aprendeu botar na prática, no dia a dia. (DSC D).

\section{- Sentimentos gerados pelas vivências do curso}

Eu acho que esse curso envolve muitas coisas, envolve a razão, envolve muita emoção quando a gente lembra das coisas das nossas dores psíquicas. Com certeza, e o curso foi muito gratificante, quero agradecer a vocês que ajudaram, com essa alegria, comunicação, ajudaram a gente, a mim a resgatar essa pessoa e vivenciar o passado. (DSC E). 
Tema 2 - Encontro da criança interior e a relaçáo com autoestima.

\section{Resultados Quantitativos}

Gráfico 2 - Proporção de ideias centrais frente ao Tema 2 - Encontro da criança interior na relação com autoestima, Ceará, 2014

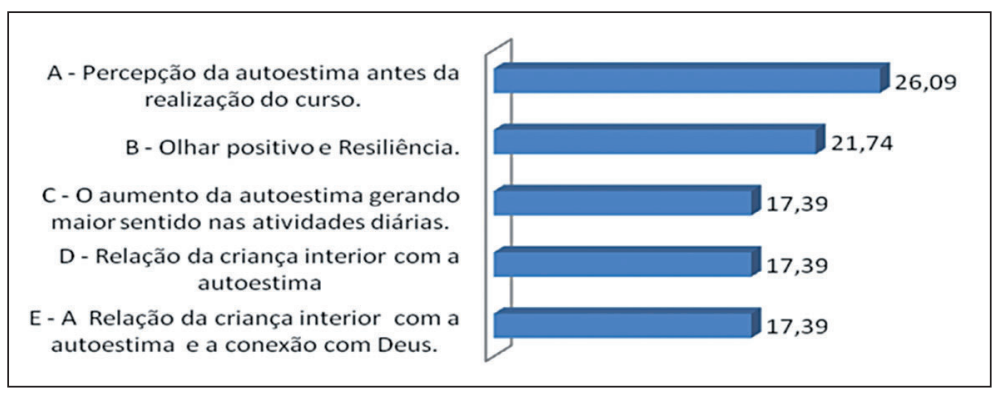

Fonte: Elaboração própria.

\section{Resultados Qualitativos}

\section{- Percepção da autoestima antes da realização do curso}

Embora eu tivesse potencial para fazer, sempre fazia as coisas e me retraia para náo aparecer. Eu pensava: e não sou boa. Hoje sinto que eu tenho a minha autoestima baixa eu tô sempre achando que eu não faço melhor. Uma descoberta pra mim foi que eu tenho que trabalhar essa autoestima eu sou capaz de dar muito, tenho a capacidade de compreender, mas eu vou ter que trabalhar isso no meu dia a dia eu não vou sair curada daqui eu tenho que trabalhar isso. É um processo, eu tenho que me ajudar a desenvolver isso. (DSC A).

\section{- Olhar positivo e resiliência}

[...] esse é o mais bacana assim, da minha história, né? Que eu tenho certeza que eu vou conseguir e acho que isso é um grande aprendizado para mim, voltar no tempo revisitar esses espaços, onde a gente teve muita dor, mas sobreviveu e, também mostrar pra gente ver, o quanto pode ser forte também, e que também pode dar conta de muita coisa não é? Eu acho que é a leveza, o amor, a troca. Porque antes eu dava muito e não me permitia muitas coisas. Às vezes, as pessoas agradeciam e eu dizia: não eu náo fiz nada não [...] (DSC B). 


\section{- $\mathrm{O}$ aumento da autoestima gerando maior sentido nas atividades diárias}

É esse resgate dessa autoestima, hoje eu percebo que essa autoestima ela é minha criança, né? Porque eu vivo aquilo que é de uma pessoa adulta, as obrigaçóes de casa, os filhos, marido, a vida profissional. Você ir fazer o esporte porque faz bem e a diferença de você ir fazer o esporte por que o coração vai junto. (DSC C).

\section{- Relação da criança interior com a autoestima}

[...] eu descobri essa criança, eu consegui dizer: nossa ela existe! Sim essa criança sou eu! Por isso foi assim tão libertador, assim, tão único o momento assim de segurar na mão, de ouvir ela dizendo: te liga, você também merece, também pode! Isso é que foi legal achar a "ferida" e descobrir novamente a criança interior, e trazer para os dias de hoje, e a consciência do que é que eu tenho que mudar para poder sair daqui com a autoestima alta. Aí sim, eu consegui ver um pouco de ânimo de felicidade! Eu acho que foi isso que o curso me proporcionou. Eu estou com autoestima alta. (DSC D).

\section{- A relaçáo da criança interior com a autoestima e a conexáo com Deus}

Eu acho que tem um grande curador de todas as nossas feridas que é Deus, esse Deus amoroso é o único capaz de curar profundamente todas as nossas feridas e transformá-las em pérolas em nossas vidas. Mas Deus não faz nada sem a nossa colaboração! ... Quando a gente traz essa criança pra dentro da gente, a gente traz Deus também. Porque parece que estamos nós e Deus. A sensação é que a gente está aqui e Deus está bem longe, lá no céu, mas Deus não ajuda quem não se ajuda. É essa a força que Deus dá. Eu vejo Deus nessa criança! (DSC E). 
Tema 3 - $O$ encontro da criança interior e a relaçáo com o estresse.

\section{Resultados Quantitativos}

Gráfico 3 - Proporção de ideias centrais frente ao Tema 3- O encontro da criança interior na relação com o estresse, Ceará, 2014.

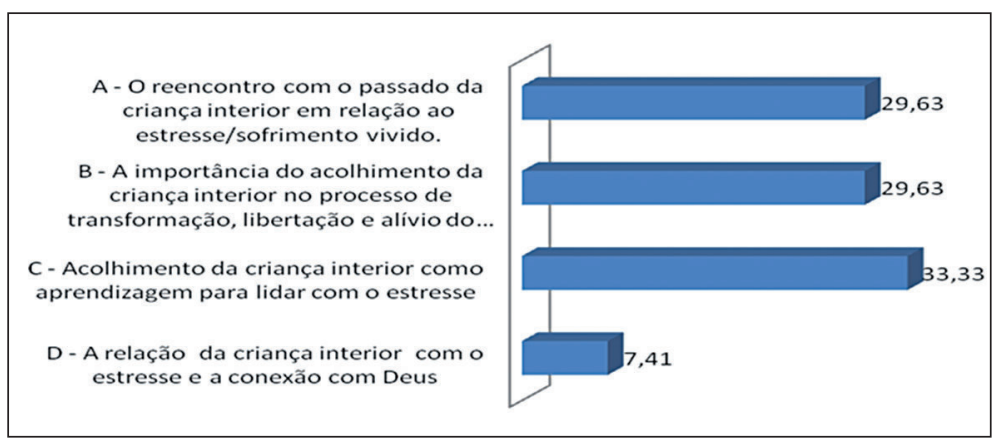

Fonte: Elaboração própria.

\section{Resultados Qualitativos}

\section{- O reencontro com o passado da criança interior em relaçáo ao estresse/ sofrimento vivido}

Eu achava que eu era capaz de tudo, o parto para mim deve ter sido muito difícil... Eu comecei a me arrastar pelo chão, comecei a bater e jogar as pernas de um lado e para outro e fui me arrastando, me movimentando e saindo. Eu acho que esse é o movimento que eu tenho que fazer, eu tenho que sair do útero da minha máe pra sair, é o resgate dessa criança. No resgate da criança eu consegui iniciar o meu movimento, para mim, no curso Cuidando do Cuidador, e náo porque eu preciso cuidar de outras pessoas. Eu sabia que tinha essa criança dentro da gente e ter que resgatar o que acontece na vida intrauterina é muito mais amplo do que na vida, do que acontece hoje, mas eu nunca tinha feito uma terapia para resgatar a criança. Eu gostei muito de ter feito esse trabalho, foi muito bom, acho que eu não resgatei total a minha criança, mas muita coisa eu pude ver e isso aflora. (DSC A). 


\section{- A importância do acolhimento da criança interior no processo de transformaçáo, libertaçáo e alívio do estresse}

Primeiro você tem que ir lá nesse resgate dessa dor e dizer: olha eu te perdoo, me perdoo por tudo que fiz acho que a sua dor é a minha dor, mas vamos comigo, cresce comigo porque eu preciso! Hoje eu consigo ver, você é a criancinha aí dentro que tá falando isso. Mas eu falava pros outros e não fazia isso comigo, eu não conseguia nem me olhar no espelho. O processo aqui é muito doloroso, foi muito sofrido pra mim, me deixar ser acarinhada, foi difícil, eu me senti um "porco espinho", mas foi um reencontro de mim mesma. O resgate de que EU POSSO. Eu posso mudar isso, eu posso me curar! (DSC B).

\section{- Acolhimento da criança interior como aprendizagem para lidar com o estresse}

Eu sinto menos estresse, acho que o curso fez com que cada um descobrisse qual foi a motivação para gerar aquele estresse. Sinto que da mesma forma que quando cheguei aqui, desmotivada, triste e tô saindo diferente. Não tenho que ir num médico ou tomar remédio, é justamente a questão emocional, que ás vezes, é alguma coisa emocional que você tá tratando. Acho que em toda minha história, nem na minha infância, eu sabia que tinha uma criança, e acaba sendo um paradoxo porque como é que eu acho que todo mundo tem menos eu, porque eu não mereço.... Que história é essa! (DSC C).

\section{- A relação da criança interior com o estresse e a conexáo com Deus}

[...] Aqui fui me perguntando e procurando essa minha criança, descobri também que essa criança é o nosso "colegamento" (ligação) com o Deus de cada um. Hoje eu tô vendo isso táo mais leve, táo mais solto. Sem culpa, sem ter que corresponder a esse Deus, sem ter que fazer coisas para que agradar e ao mesmo tempo táo gostoso, sentindo a presença Dele que parece que foi também uma libertação tudo isso. (DSC D).

O resultado qualitativo por meio do grupo focal apontou uma melhora na autoestima dos participantes, bem como alívio no nível de estresse em relação a como chegaram para o curso. Essa diferença se deu pela consciência da existência da criança interior e a aprendizagem, durante 
o curso, de reconhecer a manifestação e acolhê-la em momentos de dificuldades e no próprio cotidiano da vida adulta. Reconectar-se e aceitar o passado apontou um caminho para resiliência.

\section{Discussáo}

O Curso Cuidando do Cuidador trabalhou com o foco ativo no resgate e acolhimento da criança interior para melhora da autoestima e alívio do estresse. Barreto (2009) propóe um aspecto importante em relação à autoestima dos participantes: a autoestima passa pela rede relacional do sujeito, ou seja, a consciência que se tem de si nasce de uma relaçáo de comunicação com outro. E é dessa relação que o autor aponta dois questionamentos importantes: Quem sou eu? Do que sou capaz? Esse caminho se torna possível, quando a pessoa se dispóe a revisitar a infância e dá voz para a criança interior proposta, inicialmente, pelo psicanalista alemão Carl Jung.

Segundo Abrams (1999, p.11), a criança interior traz em si uma mensagem bem sutil: "[...] todos nós carregamos aqui dentro uma criança eterna, um jovem ser inocente e maravilhoso. E essa criança simbólica também nos carrega, carrega quem fomos o registro de nossas experiências de formação de nossos prazeres e dores." Dentro desta consciência e foco, observou-se que o estresse é um dos fatores, que mais implicam nas experiências do indivíduo com a criança interior no curso. O período da infância abrange, durante a vida de um indivíduo, desde seu nascimento até, aproximadamente, o completar dos doze anos de idade. Ao longo deste período ocorre todo o desenvolvimento físico e psicológico do ser, marcado pelas principais mudanças não apenas de seu corpo, mas principalmente da construção de sua personalidade. Partindo-se dos trabalhos desenvolvidos por Jung, o motivo da criança se tornou abrangente não apenas do plano pessoal, como o registro individual, de cada um, mas do plano coletivo, em funçáo dos registros da humanidade. Pereira (2008, p.10) disserta que: "[...] no interior de cada pessoa, existe a sua própria criança e a criança comum a todos os seres humanos, pertencentes à humanidade de todos os tempos."

Nos anos 1960, o conceito da criança interior se manifesta, de maneira especial, nos trabalhos de Jung publicados na edição americana de 1959 de The Psychologyof The ChilArchetype, em que a criança interior é definida como um símbolo da psique, uma tonalidade, ou seja, a criança interior estabelece uma ponte entre o plano coletivo e o plano pessoal (PEREIRA, 2008; SIMỐES, 2011). Por isso, a criança é um dos símbolos 
do Self, do si mesmo, por poder expressar a totalidade do ser humano. Quando acolhidas pela consciência, suas manifestaçóes são como um bálsamo curador. No entanto, a criança interior, por ser a parte genuína de todo o ser humano, também é aquela parte autêntica que sofre em função das dificuldades da vida. Sofre como uma criança ferida ou abandonada (PEREIRA, 2008).

Se, por um lado, o motivo da criança ferida procura representar a impotência, a dificuldade em alcançar a existência psíquica da totalidade, o desamparo daquele impulso de vida que obriga tudo o que cresce a obedecer à lei de máxima de autorrealização. Neste processo, as influências do ambiente dificultam o caminho da individuação. Por outro, o motivo da criança é, também, uma personificação de forças vitais que vão além do alcance de nossa consciência, caminho e de nossas possibilidades. Ela representa o mais forte e inelutável impulso do ser, isto é, o impulso de realizar-se a si mesmo (AMORIM, 2004; PEREIRA, 2008; SIMÓES, 2011).

Portanto, as manifestaçóes do motivo da criança apresentam tanto dificuldades no caminho da individuação quanto uma força vital inata, que impulsiona o ser humano a se conectar com o seu si mesmo, sendo um caminho para a própria individuação.

Bowen (2009) afirma que compreender o mecanismo de diferenciar-se, desfazer os triângulos e trocar os velhos modelos não é, unicamente, um objetivo terapêutico, como também a meta da vida de ser humano, que deseja conquistar a liberdade e o conhecimento em um sistema aberto de relaçóes. Os processos de diferenciação estão sempre em marcha, dinâmicos como o crescimento da pessoa inserida em um contexto familiar e social, em evolução, já há milhares de anos.

Desta forma, o encontro com a criança interior é destinado a pessoas adultas que buscam a expansão de suas consciências e a reconexão com o lugar, em que se encontra a alma - Self ou a si mesmo. Esse é o lugar da guarda, que cada ser humano possui, de todos os registros passados, presentes e, também, das potencialidades de seu vir a ser. É a parte em que, verdadeiramente, se tem a que contém a nossa energia vital, nossa fonte de vida. Portanto, desenvolver as potencialidades é o caminho que leva a alma a cantar com significado (PEREIRA, 2008).

$\mathrm{O}$ trabalho de resgate da criança interior desenvolvido no curso apontou para uma maior consciência do comportamento humano e a importância do autoconhecimento, bem como proporcionou o surgimento de questôes ligadas com a fé, com a religiosidade e com a espiritualidade para superação do sofrimento dessa criança ferida. 
A espiritualidade é uma das fontes primordiais de inspiração do novo, de esperança e de autotranscedência do ser humano. A espiritualidade, cada vez mais, vem sendo encarada como uma dimensão profunda do ser humano, isto é, ela também é considerada um elemento fundamental para a individuação e para conseguir a resoluçáo de conflitos e desolaçôes existenciais (BATISTA, 2007).

No Curso Cuidando o Cuidador, existem momentos de intensa espiritualidade, massagens e toques com intenção de cura. As práticas de cura pelo toque e imposição de mãos humanas para instrumento terapêutico são utilizadas desde os primórdios da humanidade (SÁ et al., 2012).

A espiritualidade pode ser uma ferramenta que auxilia o ser humano para adquirir sua própria compreensão, atingindo as esferas mais profundas de seu interior, para transcender a sua realidade. A espiritualidade pode ser entendida como uma arte, como o saber que vai além das realidades percebidas, habitualmente, está fora do comum. Para enfrentar os problemas do cotidiano, a fé é apontada como uma das estratégias mais usadas, e em muitos casos, é uma das únicas ferramentas para resolver o problema vivido (SÁ et al., 2012).

Observa-se que os próprios participantes passaram a interagir com os resultados do curso com percepçóes positivas em relação ao estresse a autoestima, de forma positiva, demonstrando aprendizagem de estratégias de resiliência.

Durante a vida é impossível náo passar por qualquer tipo de adversidade. Angst (2009) descreve que uma das razóes para que um mesmo evento gere consequências diferentes a determinadas pessoas que se relaciona ao conceito de resiliência. Esta seria definida como uma capacidade universal que possibilita a pessoa, grupo, ou comunidade prevenir, minimizar ou superar os efeitos prejudiciais causados pelas adversidades, inclusive, com a capacidade de passar por essas situaçóes e sair fortalecida, ou transformada, porém não ilesa.

Um aspecto-chave da resiliência é a capacidade de lidar com o estresse de um modo de vida saudável. Estresse pode estar fisicamente e psicologicamente prejudicial, mas a resiliência pode ajudar a prevenir e proteger contra os efeitos negativos do estresse (MCEWEN, 2006).

Pessoas que são psicologicamente reativas tendem a ter mais respostas fisiológicas, enquanto aqueles que são psicologicamente mais "estáveis" também têm mais estabilidade e menor reatividade em suas respostas fisiológicas para estresse, por exemplo, indivíduos que sofrem de ansiedade, depressão, solidão e baixa autoestima estão inclinados a perceber as circunstâncias como uma ameaça muito maior do que é justificável (FREDRICKSON, 2013). 
Nos estudos das influências de fatores ambientais sobre características psicológicas inatas, a resiliência já foi definida como o desenvolvimento normal sob condiçóes difíceis. Estas eram denominadas como fatores de risco, estudadas por pesquisadores em psicopatologia do desenvolvimento, identificados como aqueles que aumentam a probabilidade de uma pessoa desenvolver problemas de comportamento ou emocionais. Dentre os fatores de risco, Souza e Cerveny (2006) apontam aqueles associados com a vulnerabilidade e predisposiçóes individuais, e os ambientais, que potencializavam o estresse, tais como: pobreza, doença mentais ou físicas, entre outros.

Angst (2009) cita Rutter (1985), quando afirma que a resiliência envolve fatores de proteção e fatores e risco. Os fatores de proteção seriam as influências que modificam ou melhoram a resposta de uma pessoa a algum perigo, que predispóe a um resultado não adaptativo, revertendo circunstâncias potencialmente negativas.

As pesquisas se estenderam para o estudo das reaçóes psicológicas diante de situaçôes traumáticas individuais ou coletivas, como foi o caso da pesquisa de E. E. Werner, em 1992, na ilha de Kauai, em que foi acompanhado, durante trinta e dois anos, o desenvolvimento de aproximadamente quinhentas pessoas vivendo em condiçôes de extrema pobreza, sendo precursor na utilização do conceito de resiliência no campo da Psicologia Social. Nessa situação analisada, Werner relatou que pelo menos um terço da população sofreu situaçóes de estresse, mas apesar das situaçóes de risco a que as crianças estavam expostas, estas conseguiram superar e construíram-se como pessoas (BARLACH; FRANÇA; MALVEZZI, 2008).

Balarch et al. (2008) indicam que o conceito de resiliência passou a despertar o interesse dos pesquisadores, principalmente, pela relação do termo com o conceito de risco. Posteriormente, a resiliência foi compreendida, de forma sistêmica, a partir da relação do indivíduo com o contexto. Os autores citam os estudos de Waller (2001), que compreendia a resiliência como um produto de forças multideterminado e sempre mutável que interage em um determinado contexto ecossistêmico, ou seja, o desenvolvimento é um processo contínuo de adaptação, assimilação e acomodação entre indivíduos e seus ambientes, impondo uma necessidade de abordar esse fenômeno em uma contextualização, já que o ecossistema é composto pelo ser humano e o ambiente (BARLACH et al., 2008).

Essa compreensão defende o oposto das pesquisas que pensam a resiliência como resultado decorrente dos traços de personalidade, já que este 
enfoque enfraquece a participação do contexto na produção de resiliência (BARLACH et al., 2008). Souza e Cerveny (2006) apontam que a adaptação é um conjunto de respostas de um organismo vivo, em vários momentos, há situações que o transformam, permitindo a manutenção da sua organização compatível com a vida, ou seja, a adaptaçáo resulta da interaçáo entre o sujeito e o ambiente, atingindo um grau de equilíbrio, que permite esta manutenção da vida, reafirmando a relação entre o sujeito e o ambiente.

Angst (2009) aponta outros fatores relacionados à resiliência, como a autoeficácia. Essa relação percebida atuava como forma do sujeito obter uma melhor qualidade de vida para a superação da adversidade, envolvendo diversos aspectos, como: o contexto, a cultura e a responsabilidade coletiva, proporcionando a capacidade de responder de formas diferenciadas a um fracasso. Neste trecho, relaciona-se também o conceito de "coping" à resiliência, posto que este é caracterizado como um conjunto de estratégias utilizadas para a adaptaçáo em adversidades pelas pessoas ou a administração de situaçôes estressoras, sendo que o indivíduo precisa avaliar e interpretar o fenômeno, percebendo-o. A utilização das estratégias de coping pode ser considerada como resiliente (ANGST, 2009).

As pessoas resilientes possuem características consideradas como básicas, por exemplo: autoestima positiva, habilidades nas relaçóes humanas, disciplina, responsabilidade, receptividade, interesse, tolerância ao sofrimento, dentre outras.

Entende-se, então, que a resiliência faz parte de um processo de crescimento pessoal do indivíduo. Processo este que também foi encontrado como um dos resultados do Curso Cuidando o Cuidador. Durante a semana de curso, os participantes foram tomando consciência de si e do outro. No encontro da criança interior e a relaçáo com o estresse e autoestima, observou-se o retorno, com relaçáo à resiliência dos participantes antes e após o curso, àqueles fatores considerados como protetores, que pareciam proteger a criança dos riscos, funcionando como amortecedores do impacto dos riscos. Estes eram: maior nível de inteligência, habilidade na resolução de problemas, estilos superiores de enfrentamento, senso de eficácia, autonomia e controle interno, senso de autoconceito, consciência interpessoal e empatia, boa vontade e capacidade para planejar, senso de humor, a existência de uma parentalização competente, a existência de um bom relacionamento com pelo menos um dos pais ou figuras parentais, a presença de apoio social na maturidade, por parte da esposa, família e outros, a existência de uma boa rede de relacionamentos informais, boas experiências escolares, envolvimento em atividades religiosas, apa- 
rência física atrativa (fator facilitador) (YUNES, 2003; ANGST, 2009). Já se sabe que o indivíduo vivencia o contexto em que está inserido, bem como a sua formação social e cultural vão formando seu caráter, sua ética e seu conceito de moral. De acordo com Pratta e Santos (2007), a psicologia também comprovou que a forma como os traumas e sofrimentos do passado são encarados poderão ser responsáveis por reaçôes futuras, exemplo disso são atitudes de adultos violentos, que sofreram algum tipo de abuso moral em famílias desestruturadas.

Por outro lado, os fatores de risco não são uma certeza, isto é, não são todas as pessoas em situaçóes estressantes que serão resilientes, tampouco que os fatores de proteção reduzem o impacto dos fatores de risco, reduzindo sempre as reaçôes negativas em exposição à situação de risco, criando oportunidades para reverter os efeitos do estresse (ANGST, 2009). A autora argumenta que é importante salientar que a resiliência não pode ser considerada um escudo protetor, como se nenhum problema fosse atingir essa pessoa, fazendo com que ela se torne rígida e resistente a todas as adversidades. Náo existe uma pessoa que seja resiliente, mas sim, pessoas que estão resilientes. Para a autora, esse processo é dinâmico, sendo que as influências do ambiente e do indivíduo se relacionam de maneira recíproca, para que o indivíduo identifique qual é a melhor atitude a ser tomada em determinado contexto.

Em suma, nota-se que um dos dados mais interessantes encontrados neste estudo se apresenta a constatação de que quanto mais se trabalha a autoestima, por meio do desenvolvimento da resiliência, menor é o nível de estresse no indivíduo e vice versa, porém os resultados significativos desse estudo devem ser interpretados com cautela. Sugerem-se mais pesquisas relacionadas ao tema, pois a metodologia utilizada náo garante uma generalizaçáo dos resultados. Vale apontar, ainda, que houve muita dificuldade de comparação dos resultados com a literatura, em relação à temática da criança interior e o próprio Curso Cuidando do Cuidador.

Como implicaçôes para futuras pesquisas, sugere-se que dois ou mais grupos focais sejam realizados para comparar os resultados.

\section{Conclusão}

A pesquisa apontou que, por meio do resgate e acolhimento consciente da criança interior foi possível aliviar o estresse gerado pelo sofrimento e melhorar a autoestima. Cada participante pode dar sentido a seu sofrimento, pode fazer uma reflexáo sobre a dor que carregava no presente ligando-a ao seu contexto histórico, aprendendo a desenvolver novas 
estratégias de resiliência. $\mathrm{O}$ resultado desse estudo permitiu recomendar a todos os cuidadores, que encontrem um espaço para o autocuidado e autoconhecimento, enquanto cuidam de outras pessoas.

\title{
SELF-ESTEEM, STRESS AND RELATIONSHIP WITH THE INNER CHILD
}

\begin{abstract}
The aim of this study was to understand the relationship of the inner child with self-esteem and the course participant stress taking care of the caregiver. 11 participants were assessed through focus group conducted after the course week. To analyze the opinions collected was used Qualiquantisoft program, the software developed by Lefevre and Lefevre whose methodology is called the Collective Subject Discourse (CSD). Upon analysis was proven that after participating in the course subjects achieve improved self-esteem, reduced stress from the meeting with the inner child. The results also pointed to higher propensity resilience.
\end{abstract}

KEYWORDS: Self care. Self concept. Psychological stress. Therapy.

\section{REFERÊNCIAS}

ABRAMS, J. (Org.). O reencontro da criança interior. São Paulo: Cultrix, 1999.

AMORIM, G. G. de. Um homem e sua psicologia: reflexôes sobre o processo de individuação em C. G. Jung. 2004. 106f. Trabalho de Conclusão de Curso (Graduação em Psicologia) - Faculdade de Ciências e Saúde, Centro Universitário de Brasília, Brasília, 2004.

ANGST, R. Psicologia e resiliência: uma revisão de literatura. Psicologia Argumento, Curitiba, v.27, n.58, p.253-260, 2009.

BARRETO, A. P. Terapia comunitária passo a passo. Fortaleza: LCR, 2009.

BARLACH, L.; LIMONGI-FRANÇA, A. C.; MALVEZZI, S. O conceito de resiliência aplicado ao trabalho nas organizaçóes. Revista Interamericana de Psicologia, Austin, v.42, n.1, p.101-112, 2008. 
BATISTA, P. S. S. A espiritualidade na prática do cuidar do usuário do Programa Saúde da Família, com ênfase na educação popular em saúde. Revista APS, Juiz de Fora, v.10, n.1, p.74-80, 2007.

BOWEN, M. De la familia al individuo: la diferenciación del sí mismo en el sistema. Barcelona: Paidos, 2009.

FIAMENGHI JUNIOR, G. A.; MESSA, A. A. Pais, filhos e deficiência: estudos sobre as relaçóes familiares. Psicologia: Ciência e Profissão, Brasília, v.27, n.2, 2007, p.236-245. Disponível em: <http://www.scielo. br/pdf/pcp/v27n2/v27n2a06.pdf >. Acesso em: 7 set. 2015.

FREDRICKSON, B. L. Updated thinking on positivity ratios. American Psychologist, Washington, v.68, n.9, p.814-822, jul. 2013.

LEFÈVRE, F; LEFÈVRE, A. M. C. O que é o DSC/Qualiquantisoft. São Paulo: IPDSC, 2007. Disponível em: <http://ipdsc.com.br/ qualiquantisoft/>. Acesso em: 7 set. 2015.

MCEWEN, B. Protective and damaging effects of stress mediators: central role of the brain. Dialogues in Clinical Neuroscience, Paris, v.8, n.4, p.367-381, dec. 2006.

PEREIRA, M. G. G. O encontro com a criança interior: passaporte para a individuação. Rio de Janeiro: ISEPE, 2008.

PRADO, G. M. A. A criança interior e os seus arquétipos. Portal Educaçáo, 26 out. 2013. Disponível em: <http://www.portaleducacao. com.br/psicologia/artigos/51356/a-crianca-interior-e-os-seus-arquetipos >. Acesso em: 23 jul. 2015.

PRATTA, E. M. M.; SANTOS, M. A. dos. Família e adolescência: a influência do contexto familiar no desenvolvimento psicológico de seus membros. Psicologia em Estudo, Maringá, v.12, n.2, p.247-256, 2007. Disponível em: <http://www.scielo.br/scielo.php?script=sci_arttext\&pid $=$ S1413-73722007000200005>. Acesso em: 7 ago. 2015 .

SÁ, A. N. P. et al. Conflitos familiares abordados na terapia comunitária integrativa. Revista Eletronica de Enfermagem, Goiânia, v.14, n.4, p.786-793, dez. 2012.

SIMÓES, H. G. M. Arteterapia: um lugar de encontro com a criança interior. Trabalho de Conclusão de Curso (Especialização em 
Arteterapia) - Instituto Superior de Estudos Pedagógicos, Rio de Janeiro, 2011.

SOUZA, M. T. S.; CERVENY, C. M. O. Resiliência psicológica: revisão de literatura e análise de produção científica. Revista Interamericana de Psicologia, Austin, v.40, n.1, p.119-126, 2006.

WALLER, M. A. Resilience in ecosystemic context: evolution of the concept. American Journal of Orthopsychiatry, Menasha, v.71, p.290297, 2001.

YUNES, M. A. M. Psicologia positiva e resiliência: o foco no indivíduo e na família. Psicologia em Estudo, Maringá, v.8 n.esp., p.75-84, 2003. 